\title{
Strategy of Spatial Panel Estimation: Spatial Spillovers Between Taxation and Economic Growth
}

\author{
K. Kopczewska ${ }^{1} \cdot$ J. Kudla $^{1} \cdot$ K. Walczyk ${ }^{2}$
}

Received: 12 January 2015 / Accepted: 1 October 2015 /

Published online: 14 October 2015

(C) The Author(s) 2015. This article is published with open access at Springerlink.com

\begin{abstract}
Spatial panels are a powerful econometric tool for the estimation of spacedependent cross-sectional time-series models of economic phenomena. A plethora of parameters and possible specifications require a systematic approach to estimation. This paper presents a strategy of estimation to be considered in applied research on economic policy, including the concept of spatial spillovers and its local and global effects, direct and indirect impacts, as well as the role of different spatial weighting schemes. The paper presents fiscal factors affecting GDP between the years 2002-2015 in a number of European economies.
\end{abstract}

Keywords Estimation strategy $\cdot$ Spatial spillovers $\cdot$ Spatial panel models $\cdot$ Direct and indirect impacts $\cdot$ Economic growth $\cdot$ Fiscal policy

JEL Classification $\mathrm{C} 21 \cdot \mathrm{E} 62 \cdot \mathrm{F} 43$

\section{Introduction}

Spatial panel models can be used in applied economic research to control for relationships over time, space and between units. This econometric toolbox expands previous aspatial panel models by the dimension of space. Besides well-known fixed or random effects and autocorrelation, this gives the advantage of controlling for spatial spillovers. The class of spatial panel models, built on achievements of traditional panels (e.g. Baltagi 2001) and spatial dependence models (Anselin 2003), exhibits relatively high complexity, mainly because of a plethora of parameters and possible specifications.

The paper is financed by the Polish National Science Centre as the research project No.2011/03/B/HS4/05552.

K. Kopczewska

kkopczewska@wne.uw.edu.pl

1 Faculty of Economic Sciences, University of Warsaw, Warsaw, Poland

2 Warsaw School of Economics, Warsaw, Poland 
Most specification decisions require theoretical justification, as well as good interpretation. Therefore, a deliberate strategy of estimation is a must.

In this paper we underline the strategy of estimation. We try to assess patterns and the strength of spatial relations. In the first step, we divide spatial spillovers into local effects, i.e. spillovers between close neighbors, and global effects extending to the whole territory. We assume that when the local effects prevail, neighborhood clusters are of high importance, where immeasurable effects such history, tradition and cultural similarity play a role in the transmission of the effects. We cover them with the inverse squared-distance spatial weights matrix that represents both all-to-all relations and the neighborhood clusters with stronger links. That is a novelty in the literature on spillovers. We estimate spatial spillovers effects in a spatial panel model with the spatial error and a lag to capture possible mobility of labor, capital, goods and services. In the second step, we calculate direct and indirect effects from the well-specified spatial panel model to detect the spillover impact of individual variables.

For illustrative purposes only, we studied the impact of national fiscal policies on economic performance. There is vast econometric literature evaluating the impact of tax policy on economic growth. It does not, however, take into account spatial spillovers which are supposed to be a significant element of government policy transmission to the real economy, and as such, may bias the estimators. The spatial spillover effect is viewed here as the impact of government policy in one country on performance of other economies in respect to the distance in space. The concept is much wider than the frequently used term tax (or fiscal) competition mainly because it covers not only the intended (or direct) action of the government but also any unintended (or indirect) changes of co-existing fiscal variables. Both elements taken together determine the total impact of fiscal policies on economic growth in open economies.

Spatial spillovers are determined by, inter alia, mobility of production factors, crossborder trade, interest and exchange rates differentials, as well as historical or institutional factors. It is commonly acknowledged that spatial spillovers cannot be minimized by separate action of any single government. This calls for policy coordination among governments. Tax policy in a country is not isolated (or spatially independent) but rather adjusts to tax policies of economically-linked countries (spatially dependent). This proposition is theoretically grounded since the work of Zodrow and Mieszkowski (1986), however, empirical research is focused on tax competition (see the excellent review of the literature, by Genschel and Schwarz 2011), neglecting spatial spillovers. The reason might be that classical linear models, which are traditionally used to estimate effects of tax policy with cross-border tax base mobility, are inappropriate to capture both direct and indirect effects. As Nijkamp and Poot (2004, p.118) put it : "econometrically, most studies ignore the spatial configuration of the growth process. Regions or countries are often treated as non-spatial units of observation. While panel data analysis may control for the possibility of cross-sectional heteroscedasticity, timewise autoregression, simultaneity and endogeneity, the possibility of spatial autocorrelation is rarely acknowledged".

There are few empirical studies of fiscal spatial spillovers. Hebous and Zimmermann (2013) find that the more important are the trade linkages between the euro-zone countries, the more synchronized fiscal consolidation is likely to lead to larger crosscountry spillover effects on output compared to effects of country-specific fiscal policy. Veld (2013) concludes that expenditure measures of fiscal consolidation are more 
effective than revenue-type ones in inducement of GDP spillovers. Auerbach and Gorodnichenko (2013) show there is a large cross-border effect of government spending on output growth in OECD countries, and that fiscal policy shock impact is stronger in crisis economies. Goujard (2013) points out that GDP growth in OECD countries is reduced when trading partners consolidate. He also gives a brief discussion of other estimates, obtained using either large macroeconomic models (e.g. OECD 2009; Ivanova and Weber 2011), the so called 'narrative approach' (e.g. Feyrer and Shambaugh 2012) or VAR models (Beetsma et al. 2006). By and large, all these studies find significant spillovers across borders, induced by fiscal shocks. However, none of them employ spatial econometrics methods, which, as LeSage and Dominguez (2012) suggest, might be very useful in the estimation of fiscal spatial spillovers. Romero and Burkey (2011), following LeSage and Pace (2009, p.42, 156), argue that there are at least two motivations for the use of spatial regression models: they are appropriate if (1) output growth is believed to be determined by an interaction process with neighboring countries (congestion effect), or (2) some determinants of GDP are spatially correlated but not included in the model and represented by the error term. Elhorst (2014) presents a number of applications of spatial econometric models with different combinations of interaction effects.

Basically, the state of the art is that, on the one hand, spatial effects of fiscal policy are evaluated within standard econometric modeling frameworks, and, on the other hand, the econometric literature has exhibited a growing interest in analyzing spatial data. However, until now there have been hardly any attempts to examine the impact of fiscal policy on economic activity with spatial spillovers. The novelty of this paper is hence twofold. First, it is to give complex overview of possibilities and reasons of selecting components of spatial models and defining and interpreting spillover effects. Second, it bridges the gap between spatial econometrics and fiscal spillovers by building a complex model of spatial relations between economic growth and fiscal policy in European countries in the last decade. The study aims to find the broadly defined short-term impact of tax policy on a given economy. The presented methodology and approach will be useful for policy analysts, building regression models to detect spatial and non-spatial effects of policy changes in open economies.

\section{Model Specification}

The problem presented below will be used as a case-study demonstrating the strategy of estimation of spatial models. The goal of econometric modeling was to find instant (from period to period) reaction of economies for fiscal policy changes, thus we have decided to apply a specification explaining 1-year changes in GDP with 1-year tax rate changes, controlling for the macroeconomic, institutional and financial situation. These short-term reactions are estimated including a long-term perspective as the panel covers 10 years. So the short-term reactions were averaged over the long-term period which enables an assessment of their stability and relevance (Green 2011, p.410). We expect consumers and firms to adapt to tax rate adjustments in the short term, partially due to the nature of these changes - they are an instrument of current fiscal policy and partially these adjustments are a response to cyclical fluctuations and the budgetary position of a government. For this reason, the short-term relation between GDP growth and tax rates seems to be 
justified. We expect that there exists unobserved spatial heterogeneity as well as spatial interdependence, as the Moran's I proves the spatial autocorrelation for many variables.

The general model is as follows:

$$
y_{i, t}=\alpha+\tau_{i}+\eta_{t}+\sum_{\text {and } u_{i, t}=\lambda W u_{i, t}+\varepsilon_{i, t}}^{K} \beta X_{k, i, t}+\rho W y_{i, t}+\sum_{k=1}^{K} \theta W X_{k, i, t}+u_{i t}
$$

The estimated full model has the following form:

$$
\begin{aligned}
& \Delta G D P=\alpha+\tau_{i}+\eta_{t}+\rho W \Delta G D P+\beta_{1} G D P(U E=100)+\beta_{2} \Delta G D P_{t-1}+\beta_{3} \text { bondrate }+\beta_{4} \text { tauCONS }+ \\
& +\beta_{5} \text { tauCAP }+\beta_{6} \text { tauWORK }+\beta_{7} \Delta \operatorname{tau} C O N S+\beta_{8} \Delta \tan K A P+\beta_{9} \Delta \text { tauWORK }+\beta_{10} \text { alpha }+\beta_{11} \\
& + \text { Herfindahl }+\beta_{12} \text { eurozone }+\beta_{13} \text { EU }+\beta_{14} \text { unemployment }+\beta_{15} \text { INVESTpos }+\beta_{16} \text { export } 2 g d p+ \\
& +\beta_{17} \text { import } 2 g d p+\beta_{18} \text { grossdebt } 2 g d p+\beta_{19} \text { domdem } 2 g d p+\beta_{20} \text { netLEND_BORROW } 2 g d p+ \\
& +\beta_{21} \text { invest } 2 g d p+\beta_{22} \text { savings } 2 \text { income }+\theta_{1} W G D P(U E=100)+\theta_{2} W \Delta G D P_{t-1}+\theta_{3} \text { Wbondrate }+ \\
& +\theta_{4} \text { WtauCONS }+\theta_{5} \text { WtauCAP }+\theta_{6} \text { WtauWORK }+\theta_{7} W \Delta \tan C O N S+\theta_{8} W \Delta \text { tauKAP }+ \\
& +\theta_{9} \text { W } \triangle \text { tauWORK }+\theta_{10} \text { Walpha }+\theta_{11} \text { WHerfindahl }+\theta_{12} \text { Weurozone }+\theta_{13} W E U+ \\
& +\theta_{14} \text { Wunemployment }+\theta_{15} \text { WINVESTpos }+\theta_{16} W \text { export } 2 g d p+\theta_{17} W \text { import } 2 g d p+ \\
& +\theta_{18} \text { Wgrossdebt } 2 g d p+\theta_{19} \text { Wdomdem } 2 g d p+\theta_{20} \text { WnetLEND_BORROW } 2 g d p+\theta_{21} \text { Winvest } 2 g d p+ \\
& \theta_{22} \text { Wsavings } 2 \text { income }+u
\end{aligned}
$$

with the error term given as:

$$
u=f(W \cdot u, \mu)+\varepsilon,
$$

where $W$ is the spatial weights matrix, with $W u$ being the autocorrelated spatial error, $\tau_{i}$ and $\eta_{t}$ are specific effects in space $(i)$ and time $(t), \varepsilon$ is the random term, $t-1$ is the index of the time lag and - if not mentioned $-t$ is assumed. Spatial error autocorrelation will be modeled in two ways (Baltagi vs Kapoor), so the general form of spatial relations is assumed in this equation.

In this specification we add regional characteristics to control for regional composition effect in:

a) process of convergence as the rate of GDP growth $(\triangle G D P)$ depends on the GDP relative value $(G D P(U E=100))$;

b) process of path-dependence with a time lag of GDP growth $\left(\triangle G D P_{t-1}\right)$;

c) process of spatial spillover with a spatial lag of the dependent variable $(W \cdot \Delta G D P)$, spatial autocorrelation of the error term $(W u)$, spatial autocorrelation of explanatory variables $(W X)$ and the impacts.

Fiscal policy is reflected by levels of tax rates (tauCAP, tauWORK and tauCONS) as well as short-term fiscal reactions (differentials) of the implied tax rates: $\triangle$ tauCONS, $\triangle$ tauCAP and $\triangle$ tauWORK. The other variables describe a possible impact of the general economic situation on the GDP change.

In order to explain the growth rate of GDP the following groups of variables have been used:

a) core variables, i.e. the time lag of GDP growth rate and tax rates on consumption, capital and labor; 
b) macroeconomic variables, i.e. the unemployment rate and exports, imports, gross debt, domestic demand, net debt, investments and savings in relation to GDP;

c) financial market variables: the Herfindhal index for bank loans market, alpha as a measure of the country internationalization, the membership in the euro area, interest rate on bonds and investment position.

The choice of variables allows for a relatively immense control of economic processes.

We study the panel for $T=10$ years (2002-2011) and $N=34$ European countries that allows for application of the spatial panel estimation method. The data were collected from Eurostat, IMF and ECB databases. From the Eurostat database come the following: consumption (tauCONS), capital (tauCAP) and labor (tauWORK) implied tax rates, prices of 10-year treasury bonds (bondrate), domestic demand calculated according to the PPS as a share of GDP (domdem $2 g d p$ ), exports and imports to GDP (export $2 g d p$, import $2 g d p$ ), and the annual growth rate of GDP ( $\Delta \mathrm{gdp})$. From the ECB database: internationalization of economy (alpha) calculated as a share of domestic ownership of capital relative to the sum of domestic and foreign capital, the degree of capital market monopoly (Herfindahl) calculated as the Herfindahl index for capital institutions total assets, dummy variable that specifies the membership in the euro area (eurozone), investment position (INVESTpos) calculated as financial investment relative to GDP, and savings relative to disposable income (savings2income). From the IMF database: unemployment rate (unemployment), the ratio of investment to GDP (invest $2 g d p$ ), gross state budget deficit relative to GDP (grossdebt $2 g d p$ ) and net government borrowing relative to GDP (netLEND_BORROW2gdp). Below we present the strategy of estimation which enables getting the efficient and robust result.

\section{Strategies of Spatial Panel Estimation}

In econometric modeling, when data are correlated over space and explanatory variables fail to fully cover variance and spatial relationships, it is necessary to use spatial methods which may at least solve the problem partially. The literature of the last decade has been dominated by simple short-term (one period) spatial dependence models. Last few years brought development in the class of spatial panel models. These estimators outperform the classical one (a-spatial or non-panel) as they are not biased and efficient (Elhorst 2010; LeSage and Pace 2009, p.155-158). However, this estimation technique requires to determine several specification parameters that allow for the best model fit. We propose here the multi-step procedure of selection of the model specification (Fig. 1).

Why may a strategy of estimation of a spatial panel model give rise to confusion? In simple OLS models the only decision in estimation is about keeping or dropping variables using significance criteria. In spatial panels, one must control for types of spatial weights matrix $W$, the spatial components: spatial error $\lambda W u$, spatial lag of dependent variable $\rho W y$, and spatial lags of explanatory variables $\theta W X$ (called also the Durbin component), as well as Fixed or Random Effects, the structure of the error term and spatio-temporal lags. Additionally, spatial econometric methods, by assumption, are under tested in comparison to the classical models. Thus spatial modelling has, by assumption, no clear test-based indicators what to choose, and is rather an art. That is 


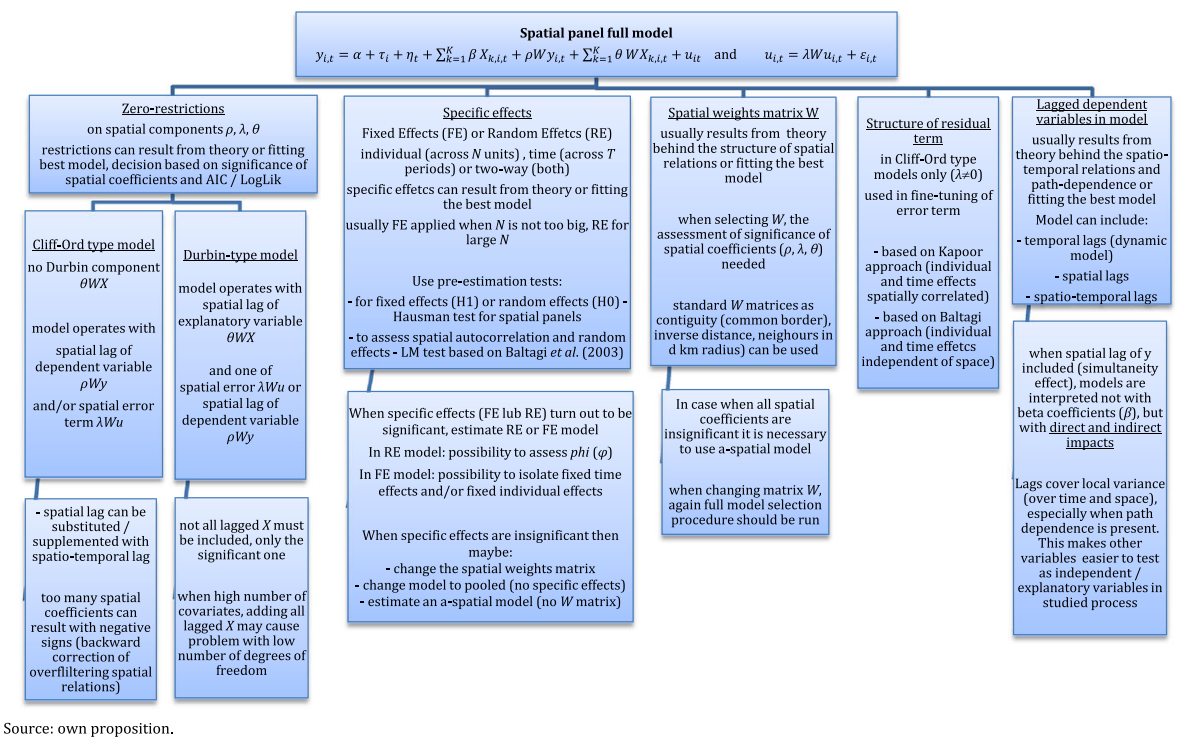

Fig. 1 Decision tree for estimation of spatial panel models

why understanding the strategy in spatial modelling is of crucial importance and makes a point in our consideration.

Below we describe aspects of using different components of spatial panel models. We follow the rule of estimation from general to specific, as it allows for selection of spatial and panel components first, and finally for variables selection. Estimation from specific to general bears the risk, that some variables are gaining or loosing their significance under different specifications. Thus starting with dropping variables under wrong spatial and panel specification may potentially cause a significant variable to be dropped. The criteria in selection of components are the AIC, LogLik and the significance test. The efficient strategy in reductions of full model (as below in Table 1) is to take decisions firstly on specific effects, secondly on spatial components, thirdly on variables and its lags, and finally on the error term structure, everything for one selected spatial weights matrix. Cross-checking is useful as well. In literature one can also find other strategies. Huang and Chand (2015) apply the strategy from middle-point up and down, which starts with an aspatial FE panel and then adds spatial components one by one and tests with the LM test if they are significant. One can also reduce insignificant variables.

\section{Estimation Issues}

As the first step, a type of the model should be selected from the Cliff-Ord-type models (Millo and Piras 2012) and the Durbin-type models (Elhorst 2009; Beer and Riedl 2012). When starting with a full model ${ }^{1}$ (also called Manski or GNS model) (Elhorst 2010), the three spatial components are included: the spatial lag of a dependent variable $(\rho W y)$, the

\footnotetext{
${ }^{1}$ Spatial models may include the spatial lag of $y(\rho)$, spatial lags of $X(\theta)$ and the spatial error $(\lambda)$, and, following Elhorst (2010), can be classified as follows: full model (GNS, Manski) with $\rho \theta \lambda$, SAC with $\rho \lambda$, SDM with $\rho \theta$, SDEM with $\theta \lambda$, SAR with $\rho, \operatorname{SEM}$ with $\lambda$, and SLX with $\theta$.
} 
Table 1 Efficient strategy of selection of components in spatial panel models

\section{Stage 1:}

From full model with initial specific effects and all spatial components

Round 1) From full model - reduction of specific effects (FE or RE) keeping all spatial components

Round 2) From reduced model - reduction of spatial components for established specific effects

\section{Cross-checking of Stage 1:}

Round 1) From full model - reduction of spatial components $(\theta, \lambda, \rho)$ keeping two-way specific effects (RE or FE)

Round 2) From reduced model - reduction of specific effects for established spatial components

Stage 1 and cross-checking of stage 1 should give similar structure of model.

Stage 2:

From reduced model with estahlished (selected) spatial components and specific effects:

Round 3) Reduction/inclusion of temporal lags and spatio-temporal lags keeping all variables

Round 4) Final adjustments of variables included in the model

Round 5) Adjustments in error term structure

Source: Own proposition

spatially autocorrelated error term $(\lambda W e)$, and a set of spatial lags of explanatory variables $(\theta W X)$. The spatial lag is understood as a weighted average of values of a given variable in neighboring locations defined by $W$. In the final model only significant $\theta W X$ should be left. This selection of $\theta W X$ means that the ratio of direct to total impact will be varying among variables. Durbin components $\theta W X$ are to cover the endogenity of regressors and local clusters in explanatory variables, and thus are treated as local spillovers. On the contrary spatial lag of the dependent variable $(\rho W y)$ is understood as a global spatial spillover and may express the long-term persistent relations in a termporal dimension. Spatial lags of error term $(\lambda W e)$ reflect the other local characteristics, exogenous shocks not modelled with variables, as they are usually unmeasurable or difficult to measure. In a case where both kinds of spillovers are possible, Mansky's full GNS model should be applied as a starting point. The spatial coefficients of $\rho W y$ and $\lambda W u$ should be analyzed jointly. In SAC or GNS models, with both $\rho W y$ and $\lambda W e$, very often the $\rho$ and $\lambda$ coefficients are very similar in magnitude but with opposite signs. Thus following LeSage (2014), the only specification which should be considered is SDEM if local spillovers are expected and SDM for global spillovers. In the final model, the positive sign of the rho reflects the clustering of similar countries or regions as well as common reactions. The negative relations demonstrate the dissimilarity - a kind of competition or the backwash effect (Kao and Bera 2013). The backwash effect is understood as an outflow of resources from one region to another. The significant and positive lambda reflects the short-term spillovers' fluctuations, similar in neighboring locations. The significant and negative lambda proves competitive mechanisms of reaction to common shocks modeled by the error term.

There are other advantages and disadvantages of using these spatial components. If the panel data contains spatial interdependence and aspatial models are being estimated, this may result in biased and inefficient coefficient estimates due to omitted variables. The Cliff-Ord-type models can correct the heteroscedasticity responsible for the bias of standard errors (Romero and Burkey 2011). The spatial error covers the spillover between idiosyncratic characteristics of units. The Durbin models, although simpler 
in estimation, may lead to lower efficiency of estimation as doubling the set of explanatory variables increases a risk of model overfitting.

In the Durbin-type model with $\rho W y$ and $\theta W X$ (SDM) the autocorrelation of spatial errors is not modeled which may lead to inefficient estimates and misleading conclusions. However, spatial lags of $X$ when required and omitted may cause a bias. Thus, Durbin models mitigate the bias of omitted and unobservable factors influencing $y$ (Le Sage and Pace 2009, p.28). Following Elhorst (2010), Durbin model's estimates are unbiased both in case of the spatial lag and the spatial error data generating process.

In this study we assume both global and local spillovers in variables and thus we start from the full GNS model. In the following steps zero restrictions are imposed on the coefficients of spatial components of the full model and special cases of the widest model estimated.

In estimation also specific effects are to be selected. Like in traditional models, these can be fixed effects (FE), random effects (RE) and models with no the specific effects (pooled). For FE models, specific effects can be estimated as the individual (for units), time (for periods), or two-way (for units and periods). In classical panels there are many tests supporting the final model selection (like Wooldridge, LM, F, Hausman tests etc.). However, in spatial methodology only few tests like Hausmann test or J test are available. The choice between the FE and RE Cliff-Ord-type models can be determined with the spatial Hausman test (Mutl and Pfaffermayr 2008). However, the decision on FE or RE may be grounded in theory. When panel units are treated as population, not a sample, FE are more suitable as they represent the unit's characteristics and stay correlated with an observed variable. RE do not change over time and are uncorrelated with the observed variable, therefore can be preferred for panels treated as a sample drawn from population.

Specific effects introduced to the model allow for controlling the characteristics of the examined dimensions. The individual effects for each observed region express stability of spatial characteristics over time, and affect the dependent variable. Their omission may result in estimation bias. Similarly, the time effects are introduced to the model for each time period. They are constant over space and represent, for instance, business cycles or changes in the institutional and legal environment. Fixed effects are simply dummy variables for each unit (spatial region or time moment) of the isolated temporal or spatial dimension, thus the constant term is omitted. In estimation, one- or two-way FE can be extracted for each individual unit with separate betas. RE give distribution instead of point estimates. Parameters of this distribution are the coefficient of RE (usually phi $(\varphi)$ ) and the standard error of the coefficient. Frequently, it happens that no significant specific effects can be found in the model, and then the pooled model is estimated. One should also observe if there appears a trade-off between significance of spatial components and specific effects. When spatial coefficients are significant only in the pooled model without FE or RE, this suggests that there exists a kind of spatial relation - differences between spatial units (e.x. countries), which can be captured in a systematic way rather than case by case (country by country).

Inclusion of fixed effects in the models is known to increase the fit of the model (Green 2011, p.370), but also to decrease the significance of variables of interest (McKinnish 2000). FE can cover time-constant and unobserved effects, but at the same time remove a great part of data variation, which can result in no impact of variables of interest. McKinnish recommends a cautious strategy of estimation as the models are very sensitive to FE inclusion. 
In this study, with a relatively short panel ( $N=34$ countries), fixed effects seem to be natural candidates, as case-by-case modelling is feasible here. There might occur tradeoff between FE and the spatial dimension in this modelling. The inclusion of FE may increase the fit, but decrease the spatial correlation and significance of tax variables.

Next, the spatial weights matrix $\boldsymbol{W}$ should be selected. One can use several types of spatial weights matrices according to various neighborhood criteria: e.g. the contiguity, inverse distance and inverse squared- (or polynomial-) distance matrices and many others. Most studies (see LeSage and Pace 2009, p. 85) use the spatial weights matrix based on the common boundary criterion (contiguity matrix) standardized by rows to unity. In some studies, an alternative matrix of inverse distance or inverse squared-distance is used. Each spatial weights matrices expresses different spatial relations, as described below.

The contiguity matrix allows for an assessment of local effects of neighbourhood spillover without taking into account the global context. The neighborhood is expressed as a dummy and takes the value 1 for a pair of regions that share a common border, and 0 otherwise. The weights are row-standardized to 1 and equal for all neighbors, regardless of the length of the border. That is, in a region which is surrounded by $n$ neighbors, each of the weights will be $1 / n$. This matrix does not include spatial relationships further than between the neighbors of the first order, i.e. sharing the same border. Second order neighborhood (neighbors of neighbors) is not taken into account. Hence, only the local spatial effects are analyzed. The advantage of applying the contiguity matrix is the ease of construction and interpretation of results.

The inverse distance matrix, with weights equal $\left(\frac{1}{d_{i j}}\right)$, where $d_{i j}$ is a distance between regions $i$ and $j$, takes into account relations of neighbors with all territorial units. These relations are linear, which means that the strength of the relationship varies proportionally to the distance. Consequently, this matrix allows for testing global spatial interaction effects without taking into account local clusters. The last matrix considered here, the inverse squared-distance matrix, with weights equal to $\left(\frac{1}{d_{i j}^{2}}\right)$, assumes that neighboring relations are nonlinear and decline quicker than proportionally to the distance. This specification allows for local clusters modeling with neighboring countries strongly related in terms of economy, culture or history. The matrix takes into account also global effects due to the non-zero weights for all units, which is usually true for open economies. It is also worth noting that in spatial econometric estimation approaches there is a stream of literature suggesting estimating $W$ rather than assuming a priori. Here one should note the Bayesian approach by LeSage and Pace (2009, p. 123) as well as technical selections with J test (Kelejian 2008).

In this study, due to the open nature of financial markets and the free flow of goods and services among all countries in the study, both global and local interactions are to be assumed as initial specification. Inversed squared distance matrix W will be tested against the simple inverse distance matrix. We do not include the contiguity matrix as it can measure only local spillover effects as the links between units do not reach further. In the squared inverse distance matrix the global links capture interactions between all units under consideration, and the local one - reflect stronger relations with the closest neighbors.

Also, a structure of the error term should be determined. There are two approaches to modeling the spatial error. The first approach, by Baltagi et al. (2003) (also Anselin et al. 2008), assumes that the error can be decomposed into individual effects 
and group effects independent of time and space, and the reminding idiosyncratic error - spatially correlated shocks (innovations) (Millo and Piras 2012). In the second approach, proposed by Kapoor et al. (2007), in the residual component both individual effects as well as the rest of the error are spatially correlated. ${ }^{2}$ These two specifications represent different mechanisms of spillovers and can be tested with LM and LR tests (Baltagi et al. 2013). Practically, the error structure by Kapoor or Baltagi is the finetuning of model specification. The order of filtering out spatial and group effects may slightly improve the quality of the error term.

In this study, there are no initial assumptions regarding the structure of error term. Both specifications will be tested and better fitted model will be selected.

As the purpose of spatial modeling is to control/filter out spatial relations (spatial trend) from the error term, and model them in a deterministic way, the models with a spatial lags are usually preferred because they can capture shocks from the error term and do not neglect significant variables. It is therefore necessary to set a strategy of including lagged variables in the model. This was referenced above as the first issue. Additionally, the decision should be made regarding the time-dimension: on time lags, spatial lags and spatio-temporal lags of a dependent $(y)$ and independent $(x)$ variables can be included. As economic phenomena are often persistent over time (pathdependence) and over space (spatial trend), separating these persistances from current variability caused by other factors is crucial for successful estimation. The time lag of the dependent variable $y$ shows temporal autocorrelation which outlines the existence of the path-dependence (strong endogenity) when significant. This happens especially when modeled patterns change slowly over time (like economic growth, unemployment rate etc.) and future values strongly depend on past values. Spatial lags or better space-time lags of $y$ cover the magnitude of $y$ variability and prevent spurious correlations, allowing for higher significance of explanatory variables. Spatial lags and spatio-temporal lags of $y$ also play the role of filters, covering autocorrelation, similar to the detrending procedure in time-series models (Anselin 2009). This means that aspatial modeling can lead to model misspecification. It may also occur in models that both coefficients (on the spatial lag and on the time lag) are needed. Including a spatial lag of $y$ from the same period (typical lag model) causes the simultaneity effect (as neighbours explain studied region and vice versa). Then there are two options: to include spatio-temporal lag of $y$, which reduces the problem of simultaneity or to use the impacts (direct, indirect and total) for final interpretation (see below).

In this study, we decided to include the temporal lag only for the dependent variable, next to the spatial lag of $y$, and the spatio-temporal lag of y was insignificant. The temporal lag of $y$ is going to compete for significance with the spatial lag of $y$ and also with specific effects. All three represent persistency: in place, over time and over space. In this study there was visible trade-off between these three elements, finally by applying the strategy of estimation, temporal lag of y proved to be most robust and significant.

Finally, spatial panel econometric methods allow for testing spatial spillover effects as well. In literature there are few attempts to operationalize this concept. The basic one

\footnotetext{
${ }^{2}$ In the literature on spatial models there is no uniform notation, i.e. Greek symbols are mixed. In this paper $\rho$ is for a spatial lag, and $\lambda$ denotes error term spatial autocorrelation. The example when symbols are used opossitely is splm package in $\mathrm{R}$ for spatial panel estimation.
} 
applied by the majority of researchers includes spatial lags of dependent variables or error terms in a model. These methods, commonly described as spatial dependence models, allow for simple testing of spillovers, mainly by checking for the significance of spatial lags coefficients (e.g. Schaltegger and Zemp 2003; Lundberg 2001). The same is proposed for the simple Durbin models, where independent variables are spatially lagged (Yuandong et al. 2013). On this basis more sophisticated models are being built. Case and Rosen (1993) propose to include a different spatial weights matrix which is dependent on location, income per capita or ethnic composition. Schaltegger and Zemp (2003) propose the spatial weights matrix of neighbors in $d$ km radius with different cut-off points, which should be checked whether results are robust irrespectively of different neighborhood criteria. Anselin (2003) proposes to distinguish local and global effects according to the rules that local spillovers appear in connected regions, and global ones also in unconnected regions. LeSage and Pace (2009, p.35) separate the mentioned above direct and indirect impacts in spatial panels for each variable coefficient. This methodology was successfully applied by Claeys et al. (2012) and then promoted by Elhorst (2009). Also, the distinction made by LeSage and Pace (2011) is possible, where global spillovers give a feedback (to the given region) and there is no local spillover feedback loop. ${ }^{3}$

\section{Post-Estimation Issues}

The procedure of finding the best fit of a spatial model is different than in other classes of econometric models. Spatial models have been available for estimation only recently, and can profit from experience of other, well developed classes of models. There has been little attempt to develop tests for model diagnostics. The first and the last test, as the admission criteria, is the Moran test for spatial autocorrelation of residuals. When the error term is no more violated by spatial autocorrelation, then the model can be considered as the final one. In the case of non-panel spatial models comparison between models which filter out error spatial autocorrelation is possible with pseudo R-squared, AIC, BIC or LogLik. For spatial panel models, the most frequent choice is LogLik in MLE, its LR test for significance of differences in LogLik in spatial and OLS models and AIC. It is very rare that LogLik and AIC give opposite recommendations. There is also a proposition by Elhorst (2009) to apply (1) the squared correlation coefficient between actual and fitted values for models without a spatial lag, and (2) $\mathrm{R}^{2}$ for transformed residuals for models with a spatial lag. In the case of spatial panels, the main method is to compare AIC and LogLik, the significance of all components as well the beta coefficients and the spatial terms coefficients $(\lambda, \rho, \varphi)$. The goal of this selection is to find a model with the highest number of significant variables, also controlling for substitution and complementarity effects of variables and spatial weights matrices. Moreover as aspatial estimates are often unbiased but inefficient, spatial

\footnotetext{
${ }^{3}$ The list of parametric spillover models is much longer. For example, Capello (2009) proposes spillovers as an index measure (variable) applied to a spatial dependence model. For regional growth this index is the average GDP of the region weighted with the distance. Reback (2007) argues for an inter-regional model of local spillovers in which an inter-regional effect comes up. His method requires the separation of natural trend (local common shocks) and spatial spillover effects. With an instrumental variable model, forecasts from inside-region units are transfered to region-border units and the difference between this forecast and observed value are modeled as a spillover effect.
} 
modeling should improve but not revolutionize estimation results Therefore, one of the indirect methods of assessing the goodness-of-fit is to compare coefficients with the simplest OLS estimates.

In this study when changing model specification following the strategy of estimation described above, we mainly analyze the changes in significance of variables and control for LogLik improvement. Admission and closing criteria - Moran test, indicates if spatial autocorrelation of residuals is still a problem in given model specification and structure.

Also, panel estimation gives consistent model coefficients for the entire test period with a single coefficient only. This advantage is simultaneously a disadvantage as it prohibits assessment of changes over time like, for example, those triggered by business cycles or financial crises. While it is possible to extract individual effects in the FE models (time and/or individual), it is impossible to get specific (individual) spatial coefficients in any panel model. However, when period-to-period changes in strength of spatial correlation are observed, then it would be possible to control for the strength of neighborhood interactions - the strength of transmission of economic phenomena between neighbors as well as interdependence of phenomena (cluster effects). This is possible in a simplified approach. Extraction of these period-toperiod neighboring effects is achieved by estimating, for each year, a simple static spatial dependence model, taking into account a spatial lag of the dependent variable. The estimation can also be based upon an approach with heteroscedastic innovation (Arraiz et al. 2010; Kelejian and Prucha 2007, 2010; Piras 2010).

In this study our purpose was to capture the transmission mechanism of taxes to the economy over a long period. This justified using only panel estimation, without tracking short-term changes in coefficients. However this study could be extended as a year-to-year analysis.

One should also remember that the beta coefficients are the traditional way of interpreting influence of an explanatory variable on a dependent variable, valid when applied to models without spatial lags of variables. However, in models with a spatial lag (SAR, SAC, SDM, GNS) in order to fully interpret an impact of changes, both in the analysed and neighborhood locations, direct and indirect impacts are to be calculated and interpreted as model coefficients. This is because the feedback loop appears when $y$ is applied on both sides of the equation, as $y$ on left-hand side and $\rho W y$ on right-hand side. Furthermore, with the Durbin component $(\theta W X)$ explanatory variables give doubled effects. Following LeSage and Pace (2009, p. 34-38) and Elhorst (2010), the direct impact (an aspatial effect) is viewed as an impact of change of $x$ in $i$ location on change of $y$ in $i$ location. The indirect effect (spillover effect) is an impact of change of $x$ in $i$ location on change of $y$ in $j$ location $(i \neq j)$. In models with a spatial lag of $y(\rho W y)$ the direct impact is the total sum of diagonal elements of the partial derivatives matrix $S_{r}(W)$ divided by $N$, calculated for a given variable, and the total impact is the total sum of all elements of this matrix divided by $N$. The indirect impact is based on off-diagonal elements and is calculated as the difference between the total and direct impact. In spatial error models, only a direct effect appears. In Durbin models (with spatial error-SDEM or without-SLX) the direct effect is given with $\beta$, and the indirect spillover effect is simply $\theta$. Thus, in spatial panel models with spatial lags, the traditional betas are only an intermediate step necessary to select the best model. Final interpretation of influence of explanatory variables on the dependent one is processed based on the impacts. However, ratio direct/indirect impact in a 
Cliff-Ord type model is constant, and only adding the Durbin-model components $\theta W x$ can differentiate impacts among variables (Elhorst 2010). Spillovers measured with impacts also have a time-dimension as the diffusion of phenomena may be simultaneous or lagged. However, this results from the significance of spatio-temporally lagged variables.

In order to understand the difference between the betas approach and the impacts approach, it is useful to conceptualize it with forecasts. In aspatial models the forecast of $y(\hat{y})$ is just the sum of products of the betas and explanatory variables. In spatial models, including a spatial lag of the dependent variable $(W y)$, the forecast is not so simple and requires a feedback loop in $y$, which is the predicted $(y)$ and predicting (Wy) variable at the same time. Adding disturbances with the spatial error term, forecasts are definitely not a simple usage of calibrated equations like in the OLS equation. In fact, forecasts for spatial models, including the feedback loop in $y$, measure the total impact which can be decomposed into the direct and indirect impacts. The significance of impact coefficients can be tested with the Bayesian or MCMC approach. While interpreting impacts, the sign and magnitude of interactions are both considered, noting that total impact is the sum of the direct and indirect impacts. The former can be strengthened by the indirect impact when both signs are the same. However, this spillover effect, measured with the indirect impact, can backwash the direct impact when signs are opposite. The spatial impact of a given variable is approximated with a share of the indirect impact in the total one. Also, the new issue of examining the bias of estimators appears. As the betas do not include the full effect of a given variable, thus the statement that omitted-variable bias exists, measured for the betas, is not suitable. Bias should be recognized with respect to the impacts, not the betas.

In this study, initial specification included spatial lag of $\mathrm{y}$ and $\mathrm{x}$, which could be the reason for applying impacts in our final interpretation. Finally, the rho coefficient became insignificant and only spatial lags of explanatory variables were kept in the model as Durbin components. Impacts are still required for analysis, but they are simply calculated as linear combinations of betas and thetas.

\section{Approach in this Study}

Despite the fact that there are numerous approaches to modeling spatial spillover effects, this issue still needs to be enhanced. Below we propose a complementary procedure of spatial spillovers' measurement and the assessment of spatial patterns. Described here is a method of understanding spillovers captured in the spatial weights matrix, spatial lags of a dependent variable, spatial autocorrelation of the error term, controlling for different specific panel effects, before the direct and indirect impacts for the final model are estimated. We argue that these impacts are a kind of aggregate coefficient values, and their significance and magnitude strongly depends on model specification. Therefore, it is crucial to model a spatial panel model with full awareness of spatial spillover mechanisms included in each separate variable, and then to automatically interpret the impacts.

We divide spatial spillovers into local effects among neighboring countries and global effects emerging over the whole territory. The first-order neighbors' interactions are considered to seize local spillovers and interdependence between all analyzed units to cover global spillovers. When local effects prevail then probably the institutional factors indirectly involved in the study such as historical, traditional and cultural 
similarity play an important role in the transmission of effects between clustered countries. When global effects play a dominant role, this is proof of open economies' interactions.

Spatial spillover effects in spatial panel models are measured by spatial components, coefficients for: the spatial error term $(\lambda)$, the spatial lag or the spatio-temporal lag of a dependent variable $y(\rho)$, and spatial lags of explanatory variables $(\theta)$. Firstly, when starting with the full model, the significance of all coefficients under given $W$ is tested. The significant $\rho$ confirms the diffusion of the process explained in the model as the dependent variable is correlated over space. When the spatio-temporal lag of $y$ is applied, it can be interpreted as path dependence and proves the persistence of the given process over time and space. The significance of $\lambda$ shows that some unexplained spatial patterns (spatial trends) exist, which usually may result from historical values, culture, climate and other omitted in the model specifications. The significance of $\theta$ confirms that explanatory variables are correlated over space, and a spillover appears not by the channel of a dependent variable, but also via explanatory variables. Secondly, the significance and the value of $\lambda, \theta$ and $\rho$ are considered under different weighting schemes. Applying a different spatial weights matrix $(W)$, may give divergent results. Of great importance is here the joint significance of $\lambda, \theta$ and $\rho$ with given $W$. In the best model, indicated by the highest significance of $\lambda, \theta$ and $\rho$, an assumed $W$ indicates the nature of spillovers and allows for interpreting whether one can detect global, local or both types of spillovers. For the well specified model, in which we can interpret the nature of spillovers, direct and indirect effects can be calculated according to the methodology of LeSage and Pace (2009, p. 41-42). The significance of impacts is similar to the significance of the betas. The difference between the betas and impacts is in magnitude of effect of $x$ on $y$, since they consume effects of $\lambda, \rho$ and $\theta$.

In this study different spillovers are captured by a few components. Squared inverse distance matrix $\mathrm{W}$ covers a range of spillovers: the global one, decaying with distance over the whole territory and the local one, intensified with closest neighbours. The Durbin component $(\theta W X)$ represents interactions between economic factors determining economic growth, by covering partly the feedback loops naturally appearing in economy. The lambda coefficient for spatial lag of error term reflects unmeasured common effects, especially in neighbouring countries because of the $\mathrm{W}$ specification. All these spillovers are then translated to direct and indirect impacts of expalanatory variables on studied phenomena.

\section{Estimation Procedure - Results and Justification}

The starting point of estimation is the full model specification. It includes: the spatial lag of the dependent variable $\rho W y$, one of the specific effects - Random Effects with their $\varphi$ coefficient or Fixed Effects (with two-way effects), error spatial autocorrelation $\lambda W u$, and all explanatory variables lagged spatially $\left(\theta_{k} W X_{k}\right)$. We adopted the estimation strategy described above, in which decisions are firstly made on specific effects, secondly on spatial components, thirdly on variables and lags, and finally on the error term structure, everything for one selected spatial weights matrix. When all spatial components are deleted, one obtains an aspatial panel, and by deleting additionally the panel structure (getting the pooled model), we obtain a classic non-panel aspatial linear model, OLS. 
Estimation results are in Tables 2 and 3 in the appendix. For the squared inverse distance matrix W (Table 2), starting model (1), GNS full model with two-way FE, was estimated and all specific effects were found insignificant. Thus, in the next model (2) only individual FE and RE effects were examined, which also turned out to be insignificant. Based on this, in the next estimation (3) the pooled model with all spatial components was selected and in consequence the spatial lag was deleted. After the fourth round (model 5) insignificant variables were deleted. We did not delete variables which were the goal variables under examination (taxes) or if one variable from a pair $(X, W X)$ was significant. For the sixth estimation, only tax variables and significant variables were left. Elimination of model components was done on the basis of its significance and LogLik. The final model (6) includes some spatially lagged $X s$ and the spatial error term. We have repeated the procedure for the simple inverse distance spatial weights matrix and we obtained the same final model specification (Table 3). Finally, we checked if changing the error term structure can influence the model. Best models (6) for both W (in the last columns) were the basis for calculating direct and indirect impacts (Table 4). The estimation strategy of the models is efficient, as it gave stable results.

For this dataset, these results confirm that the model with the spatial weights matrix based on the inverse distance criterion, with the Durbin components and the spatial error specification by Baltagi, but no specific effects (pooling), gives the best results. The obtained result stays in line with other aspatial research results. For the selected model specification, direct, indirect and total impacts were calculated (Table 4) and interpreted.

Results of the model should be analysed in two dimensions: econometric and economic ones, with several points to discuss:

Spatial parameters: The most interesting point is in the negative sign of the coefficients. Negative and significant lambda at spatial error autocorrelation reflect a pattern of inter-country competition, not clustering of similar patterns which is usually reported. This competitive behavior applies mainly to neighboring countries. A negative sign is persistent when specific effects and rho are eliminated. Inclusion of mentioned parameters changes the sign and significance of lambda and weakens the model. The second negative parameter is at the variables of interest, i.e. tax variables. This is the result of strong tax avoidance or outflow of capital and consumption to neighboring countries.

Specific effects: In the full model the RE were rejected with the Hausmann test, as the $\varphi$ coefficient was insignificant. The Hausmann test allows for a choice between FE and RE, however, if the selected specific effects become insignificant, the pooled model should be applied. Fixed effects (individual and/or time) are to absorb individual variability. In the estimated models all fixed effects (individual, time and two-way) were found to be insignificant, possibly due to too low variability between groups. In this case, only the pooled model should be estimated since the presence of insignificant fixed or random effects does not allow for modeling of both effects reliably.

Spatial weights matrix W: The spatial weights matrix is a core element of all spatial models, including spatial panel models. All-with-all connections in the inverse distance matrix were admitted a priori on the basis of the theory that European economies are inter-connected and include regional cluster effects. It is worth noting that OLS panel coefficients (Table 4) have the same sign and significance as spatial panel coefficients. Spatial coefficients when introduced to the a-spatial pooled panel, increase the total impact of variables of interest (taxes). This stronger impact of taxes, when 
neighborhood relations are assumed, may indicate local cross-border interactions, and shifting consumption as well as investment abroad in response to growing tax rates.

Error structure: Neither the Baltagi, nor the Kapoor specification of error term outperformed. We decided to leave the Baltagi error, but no changes to the model estimation would appear with Kappor specification. The model proved to be insensitive for this component.

Spatio-temporal lags: The spatial lag of the dependent variable $(W y)$ is to reflect current spatial interactions of neighboring countries, resulting from economic integration and the mobility of production factors and can be treated as an endogenous factor. As Wy was almost always insignificant, one can conclude that all interrelations between countries result from the input (market and economy conditions and determinants of GDP growth), and not the output (GDP growth). The significant time lag of $y$ shows temporal autocorrelation of the dependent variable and outlines the existence of the path-dependence. The time lag of the dependent variable covers a part of the trend, which is similar to detrending in time series analyses. There was no strong spatial trend to be covered by the spatial lag.

Goodness of fit and criteria of selection: The applied procedure was efficient in terms of dealing with the issue of spatial autocorrelation. The Moran's I test for the residuals, applied to each year separately (to cover the full range of errors), confirms that spatial error autocorrelation was filtered out. Correlations between fitted and observed values were the highest in the case of FE models, but as mentioned above all FE were insignificant and understated the magnitude of variables of interest. Thus we considered the pooled model with different specification only. The multivariate estimation and analysis of the panel models and its AIC and LogLik indicated that the best model is the pooled specification with the spatial lag. The inverse squared-distance matrix allows for control of global and local interactions. The spatial ML estimation is proper in order to eliminate the bias of parameters obtained in the classical OLS model. Comparison of the ML spatial pooled panel model incl. the spatial error with the OLS aspatial model, as in Kapoor et al. (2007), shows that the estimates of the spatial panel are on average about 0.7 the estimates of OLS.

Panel vs. period-to-period estimation: Period-to-period estimation could give an insight into track changes of coefficients for both spatial components as well the other variables. This short term analysis could answer the question, for how much special indicents on market (like crisis) impact transmission of fiscal policy. Presented model reflects long-term relation of short-term changes and allows for more general conclusions and studying patterns persistent over time.

Impacts: Lack of spatial lag of y enabled calculation of impacts as linear combinations of thetas and betas. As Table 4 reports, impacts for both models, with squared inverse distance and simple inverse distance are very similar, in significance, magnitude and sign. This supports the thesis by LeSage (2014) that spatial models are insensitive to the changes of the spatial weights matrix W. One common thing is that in general indirect effects prevail over direct effects, as the indirect coefficients are several times higher than the direct one. This would be in favour of the hypothesis that economies are very strongly inter-connected and the vast majority of changes in the parameters of one economy translates to changes in other economies.

Spillovers: The spatial spillover effect was modeled with the spatial lag of the dependent variable $(\rho)$, spatial correlation of the residual $(\lambda)$ and spatial lags of $X(\theta)$. There is a strong pattern of clustering which may stem from the sharing of successes and failures of 
economic neighbors. These interactions between the neighboring countries are stronger than amongst further located countries, which results from $W$ construction as inverse distance. This may suggest common taxation effects within strong economic and social linkages between neighbors. The negative signs of the tax rate parameters may imply strong tax avoidance or outflow of capital and consumption to neighboring countries. With the inverse squared-distance matrix, the negative spatial error autocorrelation represents competitive behavior rather than similarity in reactions. This can be an indirect evidence of the tax competition effect in neighboring countries. Also, the indirect impact was found to be much stronger than the direct one. And the decomposition into the direct and indirect effects shows that simple interpretation of OLS estimates might be misleading. The impact of taxation of labor $(\operatorname{tax} W O R K)$ in OLS is positive but the spatial panel proves that local impact is negative and the external spillover gives positive stimuli.

From an economic point of view, fiscal policy, captured by tax rates on labor (tauWORK) and capital (tauCAP), entails significant direct and indirect effects. Taxation of consumption (tauCONS) proved to have no impact on GDP growth. In case of tax on capital the impact of neighbourhood is almost five times stronger than of domestic changes. The joint impact of domestic and overall changes is visible in the case of the interest rate of bonds (Bondrate), loan market concentration (Herfindahl) and the savings-to-GDP ratio (savings $2 g d p$ ). External impact is evidenced in internationalization of economy (alpha), investment position (INVESTpos), debt and its changes related to GDP (grossdebt2gdp, netLEND_BORROW2gdp). Internal impact is visible by the channel of investments (invest $2 g d p$ ). Directions of those effects are in line with expectations: growing tax rates on consumption and capital trigger a decline of GDP. Higher cost of bonds as well as higher degree of capital market monopolization decrease the economic growth. Because of the nearly triple magnitude of indirect over direct spatial effect $(3: 1)$, these economic variables can be treated as strong spatial factors explaining economic performance. This means that on average $75 \%$ of GDP changes result from the neighborhood interactions, which in turn proves a very strong spillover effect on GDP growth. The obtained results are consistent with the findings of other studies. One can also observe convergence process as the growth rate depends negatively on the level of GDP ( $g d p U E 100$ ).

Further remarks on the results of estimation need to be made:

Role of the Capital Market The estimation takes into account the rate of the tax on capital and its changes, interest on bonds and the Herfindahl index of banking market concentration. Three out of four variables were significant and their effect on growth is negative. In the short run, higher taxation of capital with higher bond yields and higher concentration in the banking sector, lead to lower the economic growth. The dynamics of capital tax changes do not affect economic growth. Therefore, the impact on the economy via the financial market is multi-channeled. Stimulating economic growth would require a reduction in the capital tax rate accompanied by a cut in interest rates and demonopolization of the credit market.

Role of the Labor Market Many studies have confirmed that the labor market does not matter for the economic growth in the short run (Trasberg 2013). In the light of the estimation results neither taxation of labor nor the unemployment rate affects the growth of the economy. 
Role of Consumers The model takes into account the tax on consumption and the savings rate. Only savings were significantly and negatively correlated with the economic growth. In the short term, an increase in savings is correlated with a decrease in the economic growth. The consumption tax rate has an insignificant but negative impact on the economic growth and its size is ca. eight times weaker than that of the capital tax. As in the case of the capital market, there is no dependence between economic growth and tax rate changes.

Openness of Economies None of the determinats of the openness of an economy was found significant. Neither domestic demand nor the exports/imports-to-GDP ratio are important when the impact of taxes on growth is analyzed.

\section{Conclusions}

This study presents the applied estimation strategy of spatial panel modeling on the example of fiscal policy in Europe in 2002-2011. Levels and changes of tax rates are to explain the growth rate of GDP, when controlling for the economic environment. From an econometric point of view, we discuss in details plenty of issues related to specifying parameters in models. We indicate important points when setting zero-restrictions on spatial components, selecting specific effects, spatial weights matrix, and spatiotemporal lags of variables as well as the structure of the error term. We demonstrate an efficient order of selecting groups of parameters of this class of models. Different spatial weights matrices that reflect different spatial relations between countries were used: the linear inverse distance matrix which assumes global interactions (all with all) without special neighborhood effects, and the inverse squared distance matrix which allows to model local interaction effects arising from cultural, historical and economic links and not just distance, together with global interactions for all analyzed units. We find that local and global spatial spillover effects turned out to be important determinants of economic growth. Negative spatial relations hint the dissimilarity of reactions between countries which - in economic terms - is interpreted as a kind of competition or the backwash effect. We show that economies' performance is determined by the significant lambda measuring spillover effects and the significant time-lag reflecting the path-dependence and endogeneity. The spillover impact is ca. three times stronger than the direct aspatial one. This supports the use of the spatial modeling approach.

From an economic point of view, the study strives to assess determinants of the EU countries economic growth throughout the years 2002-2011 with inclusion of spatial spillover effects. The estimated models for 34 countries show that taxes on consumption, labor and capital have different effects on the GDP growth rate, assuming the control of financial markets and the macroeconomic environment. The model was estimated with the use of Eurostat, IMF and OECD databases for the period between the years 2002-2011. We confirm that increasing taxes reduces the GDP growth. The capital gains tax, along with the high concentration in the financial markets (as measured by the Herfindahl index), appear to have a negative impact on economic performance. The labor tax was found to be significant in all considered models. The consumption tax has a negative but insignificant impact. The obtained results are consistent with findings of other studies (see Shinohara 2014 for a review). 


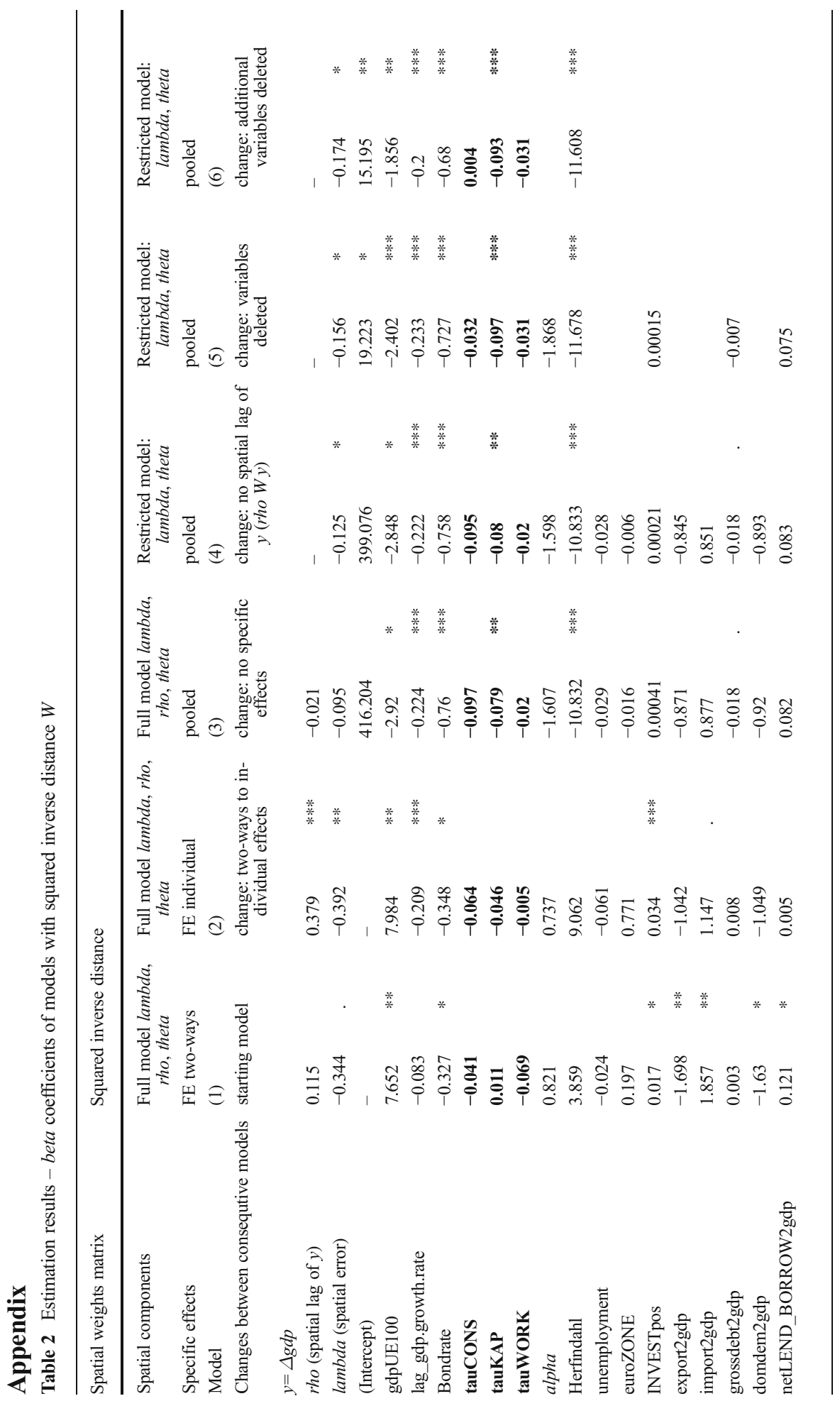




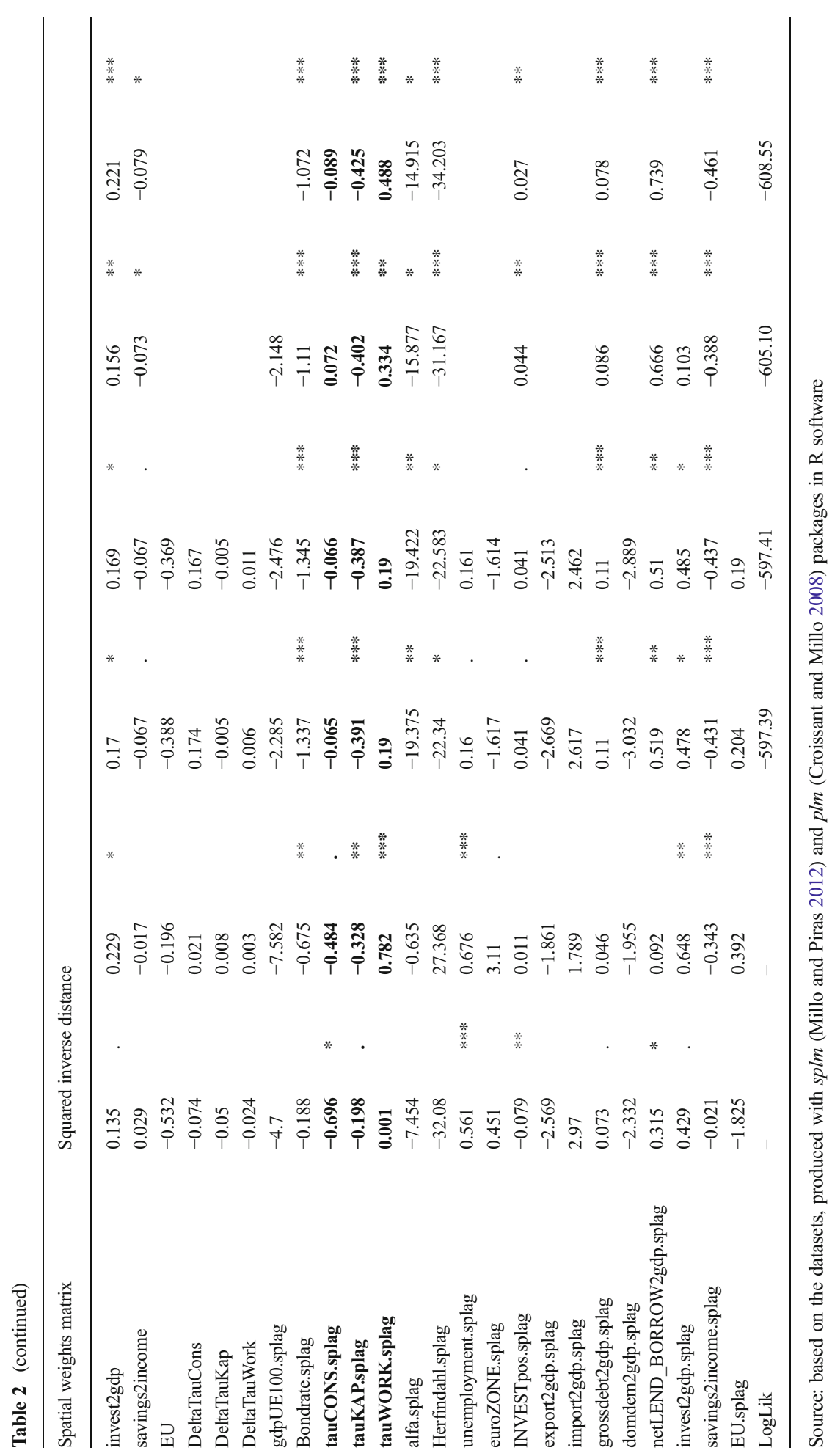




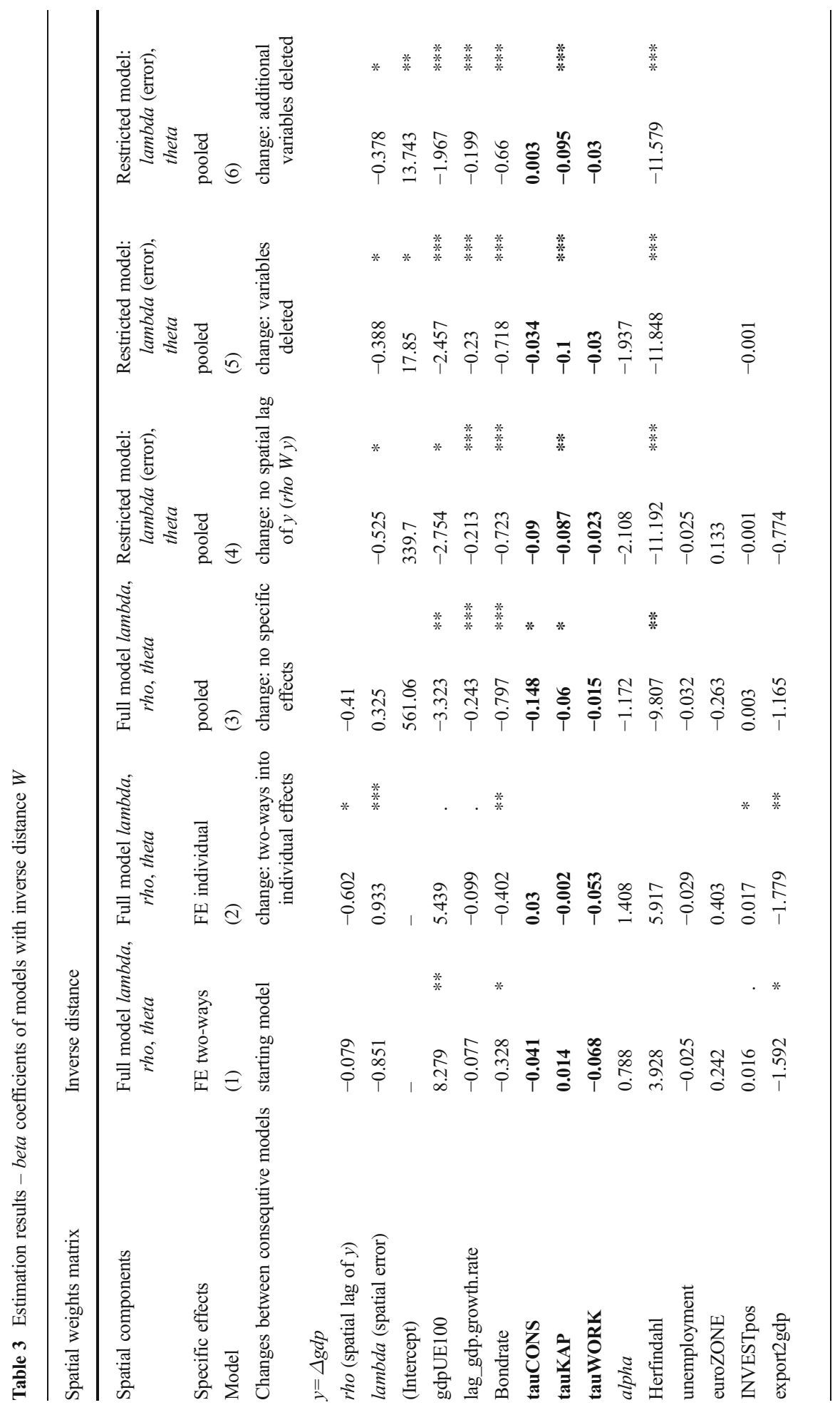




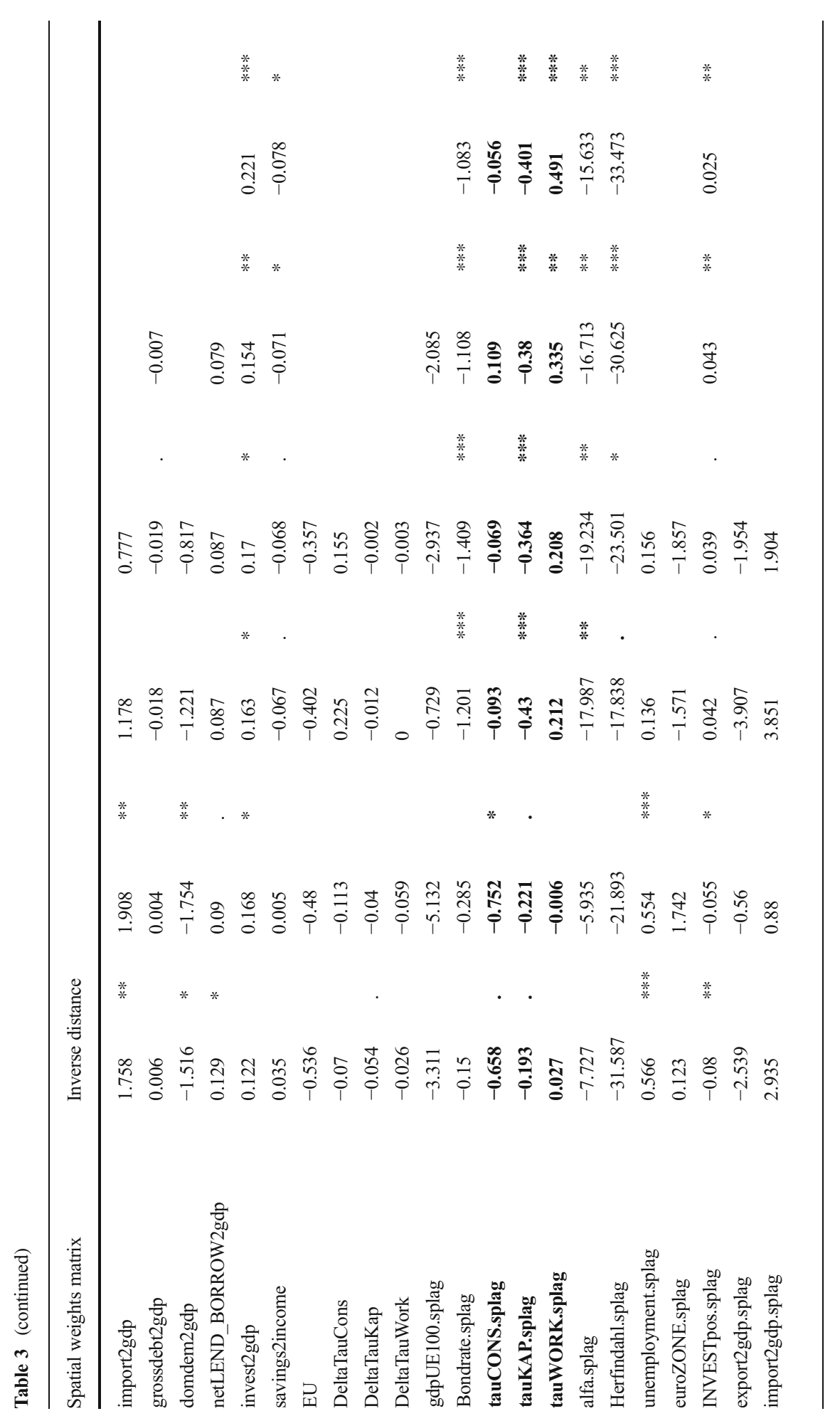




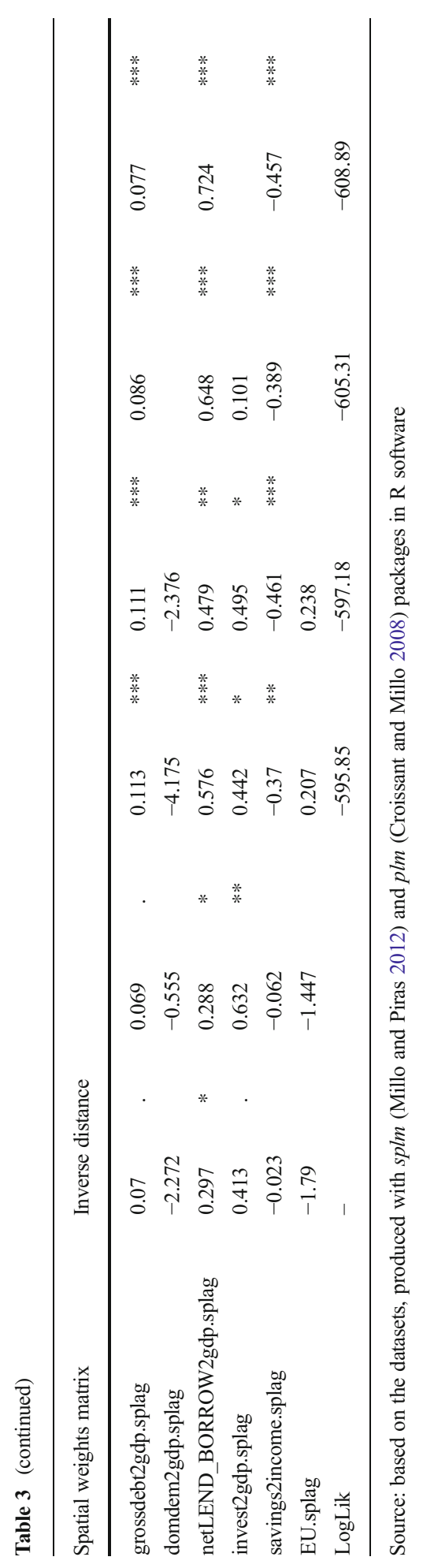




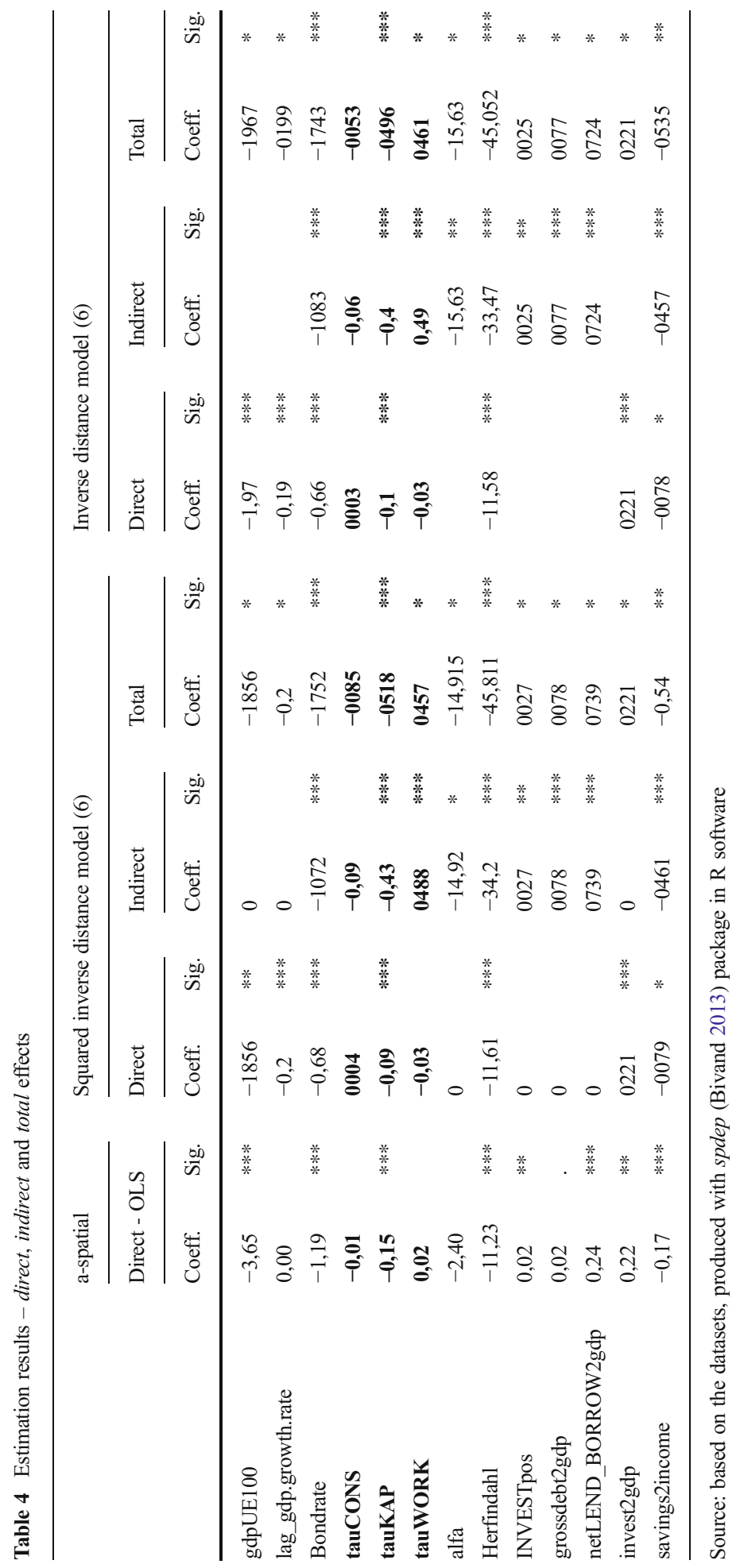


Open Access This article is distributed under the terms of the Creative Commons Attribution 4.0 International License (http://creativecommons.org/licenses/by/4.0/), which permits unrestricted use, distribution, and reproduction in any medium, provided you give appropriate credit to the original author(s) and the source, provide a link to the Creative Commons license, and indicate if changes were made.

\section{References}

Anselin, L. (2003). Spatial externalities, spatial multipliers, and spatial econometrics. International Regional Science Review, 26, 153-166.

Anselin, L. (2009). Spatial regression. In A. S. Fortheringham \& P. A. Rogerson (Eds.), The SAGE handbook of spatial analysis (pp. 255-275). Newbury Park: Sage.

Anselin, L., Le Gallo, J., \& Jayet, H. (2008). Spatial panel econometrics. In L. Matyas \& P. Sevestre (Eds.), The econometrics of panel data. Berlin: Springer.

Arraiz, I., Drukker, D. M., Kelejian, H. H., \& Prucha, I. R. (2010). A spatial Cliff-Ord-type model with heteroscedastic innovations: small and large sample results. Journal of Regional Science, 50, 592-614.

Auerbach, A., \& Gorodnichenko, Y. (2013). Output spillovers from fiscal policy. American Economic Review: Papers and Proceedings, 103, 141-146.

Baltagi, B. (2001). Econometric analysis of panel data (3rd ed.). New York: Wiley.

Baltagi, B. H., Song, S. H., \& Koh, W. (2003). Testing panel data regression models with spatial error correlation. Journal of Econometrics, 117, 123-150.

Baltagi, B. H., Egger, P., \& Pfaffermayr, M. (2013). A generalized spatial panel data model with random effects. Econometric Reviews, 32(5-6), 650-685.

Beer, C., \& Riedl, A. (2012). Modelling spatial externalities in panel data: the spatial Durbin model revisited. Papers in Regional Science, 91(2), 299-318.

Beetsma, R., Giuliodori, M., \& Klaassen, F. (2006). Trade spill-overs of fiscal policy in the European Union: a panel analysis. Economic Policy, 21(48), 639-687.

Bivand, R. (2013). spdep: Spatial dependence: weighting schemes, statistics and models. R package version 0.5-68.

Capello, R. (2009). Spatial spillovers and regional growth: a cognitive approach. European Planning Studies, 17(5), 639-658.

Case, A., \& Rosen, H. (1993). Budget spillovers and fiscal policy interdependence. Journal of Public Economics, 52, 238-307.

Claeys, P., Moreno, R., \& Suriñach, J. (2012). Debt, interest rates, and integration of financial markets. Economic Modelling, 29(1), 48-59.

Croissant, Y., \& Millo, G. (2008). Panel data econometrics in R: the plm package. Journal of Statistical Software, 27(2), 1-43.

Elhorst, J. P. (2009). Spatial panel data models. In M. Fischer \& A. Getis (Eds.), Handbook of applied spatial analysis. Berlin: Springer.

Elhorst, J. P. (2010). Applied spatial econometrics: raising the bar. Spatial Economic Analysis, 5(1), 9-28.

Elhorst, J. P. (2014). Spatial econometrics. From cross-sectional data to spatial panel series. Belin: Springer.

Feyrer, J., \& Shambaugh, J. (2012). Global savings and global investment: the transmission of identified fiscal shocks. American Economic Journal: Economic Policy, 4(2), 95-114.

Genschel, P., \& Schwarz, P. (2011). Tax competition: a literature review. Socio-Economic Review, 9, 339-370.

Goujard, A. (2013), Cross-country spillovers from fiscal consolidations, OECD Economics Department Working Papers, No.1099, OECD Publishing.

Green, W. H. (2011). Econometric analysis (7th ed.). Englewood Cliffs: Prentice Hall.

Hebous, S., \& Zimmermann, T. (2013). Estimating the effects of coordinated fiscal actions in the euro area. European Economic Review, 58(C), 110-121.

Huang, Q., \& Chand, S. (2015). Spatial spillovers of regional wages: evidence from Chinese provinces. China Economic Review, 32, 97-109.

Ivanova, A., Weber, S. (2011). Do fiscal spillovers matter?, IMF Working Papers, 11/211, International Monetary Fund.

Kao, Y-H., Bera, A. K. (2013) Spatial regression: the curious case of negative spatial dependence, working paper, University of Illinois, Urbana-Champaign. 
Kapoor, M., Kelejian, H. H., \& Prucha, I. R. (2007). Panel data model with spatially correlated error components. Journal of Econometrics, 140(1), 97-130.

Kelejian, H. H. (2008). A spatial j-test for model specification against a single or a set of nonnested alternatives. Letters in Spatial and Resource Sciences, 1(1), 3-11.

Kelejian, H. H., \& Prucha, I. R. (2007). HAC estimation in a spatial framework. Journal of Econometrics, 140, 131-154.

Kelejian, H. H., \& Prucha, I. R. (2010). Specification and estimation of spatial autoregressive models with autoregressive and heteroscedastic disturbances. Journal of Econometrics, 157(1), 53-67.

LeSage, J. P. (2014). What regional scientists need to know about spatial econometrics, Working Paper, Texas State University-San Marcos.

LeSage, J. P., \& Dominguez, M. (2012). The importance of modeling spatial spillovers in public choice analysis. Public Choice, 150(3-4), 525-545.

LeSage, J., \& Pace, R. K. (2009). Introduction to spatial econometrics. Boca Raton: CRC Press, Taylor and Francis Group.

LeSage, J. P., \& Pace, R. K. (2011). Pitfalls in higher order model extensions of basic spatial regression methodology. The Review of Regional Studies, 41(1), 13-26.

Lundberg, J. (2001), A spatial interaction model of benefit spillovers from locally provided public services. CERUM Working Paper, No. 35.

McKinnish, T. (2000). Model sensitivity in panel data analysis: some caveats about the interpretation of fixed effects and differences estimators, working paper, Boulder: University of Colorado, Department of Economics.

Millo, G., \& Piras, G. (2012). Splm: spatial panel data models in R. Journal of Statistical Software, 47(1), 138.

Mutl, J., \& Pfaffermayr, M. (2008). The spatial random effects and the spatial fixed effects model: the Hausman test in a Cliff and Ord panel model (Economics Series No. 229). Vienna: Institute for Advanced Studies.

Nijkamp, P., \& Poot, J. (2004). Meta-analysis of the effect of fiscal policies on long-run growth. European Journal of Political Economy, 20, 91-124.

OECD (2009), The effectiveness and scope of fiscal stimulus, OECD Economic Outlook, Interim Report, OECD Publishing.

Piras, G. (2010), Sphet: spatial models with Heteroskedastic innovations in R. Journal of Statistical Software $35(1)$.

Reback, R. (2007). Fiscal spillovers between local governments: keeping up with the Joneses' School District, ISERP Working Papers, No. 07-10.

Romero, A. A., \& Burkey, M. L. (2011). Debt overhang in the eurozone: a spatial panel analysis. The Review of Regional Studies, 41, 49-63.

Schaltegger, CH., Zemp, S. (2003). Spatial spillovers in metropolitan areas: evidence from Swiss communes, CREMA Working Paper, No. 2003-06.

Shinohara, M. (2014), Tax structure and economic growth - a survey of empirical analyses, Institute of Economic Research Chuo University Discussion Paper, No. 217.

Trasberg, V. (2013), Scatter view on european tax structures, in Discussions on Estonian Economic Policy: Theory and Practice of Economic Policy in the European Union, No.1, University of Tartu.

Veld, J. (2013). Fiscal consolidations and spillovers in the Euro area periphery and core, Economic Papers, 506, European Commission.

Yuandong, G., Tao, W., Wen, Y., \& Xiaohua, W. (2013). A spatial econometric study on effects of fiscal and financial supports for agriculture in China. Agricultural Economics, 59(7), 315-332.

Zodrow, G. R., \& Mieszkowski, P. (1986). Pigou, Tiebout, property taxation, and the underprovision of local public goods. Journal of Urban Economics, 19, 356-370. 